\title{
Analysis of Collision Threat Parameters and Criteria
}

\author{
Andrzej S. Lenart \\ (Gdynia Maritime University, Gdynia, Poland) \\ (E-mail: aslenart@am.gdynia.pl)
}

In this paper collision threat parameters such as the distance at closest point of approach and time to the closest point of approach are derived and analysed for special cases and features; collision criteria are analysed for limitations. A new collision threat parameter - time to safe distance - is proposed and its different applications to collision avoidance are presented. Time to safe distance can replace time to the closest point of approach, as it gives a safer time in a dangerous situation. It can be applied in Automatic Radar Plotting Aids (ARPAs) to detect dangerous objects and to display possible evasive manoeuvres.

KEY WORDS
1. Collision avoidance.
2. Approach parameters.
3. Collision criteria.
4. Predicted areas of
danger

Submitted: 17 August 2014. Accepted: 4 March 2015. First published online: 26 March 2015.

1. INTRODUCTION. The predicted object CPA (Closest Point of Approach) distance $\mathrm{D}_{\mathrm{CPA}}$ and, to a lesser extent, the time interval to its occurrence $\mathrm{T}_{\mathrm{CPA}}$ are wellestablished approach parameters used in collision avoidance systems featuring Automatic Radar Plotting Aids (ARPAs) as well as in manual radar plots.

After the introduction of marine navigation radars for collision avoidance purposes, approach parameters of tracked objects were determined in a graphical manner by manual radar plots. At the beginning, analytical formulae for determination of motion and approach parameters and collision avoidance manoeuvres were derived in a polar coordinate system, natural for radar plots, with input values such as distances, bearings, speeds, courses and their changes.

The introduction of computer controlled ARPAs has created the need for algorithms for determination of motion and approach parameters but calculations in such systems are system-specific because they use mainly a Cartesian coordinate system. This is caused by:

- simple equations of motion in a system of Cartesian coordinates,

- simple estimation algorithms for motion parameters in digital tracking filters (because for objects travelling with constant velocities and courses their polar 
position changes - radial and angular velocities - are not constant but in Cartesian coordinates are constant),

- reduction of number of trigonometric and circular functions which, when used in numerical calculations, are connected with longer and less accurate calculations.

Publication of such algorithms is very rare - Jakševič (1967) and Lord (1968) are two of the very few that have been published - and they are without any analysis of features and special cases, which are essential in computer calculations. In Sections 2 to 4 equations for $\mathrm{D}_{\mathrm{CPA}}$ and $\mathrm{T}_{\mathrm{CPA}}$ are fully derived and analysed, including their special cases and features.

Apart from conventional ARPA displays (vectors only) there are two unconventional ones: Firstly, PADs and PPC (Predicted Areas of Danger and Predicted Points of Collision) in circles, ellipses or hexagons (Riggs, 1970; 1975; Riggs and O'Sullivan, 1980; Fleischer et al., 1970, Cornett et al., 1979) which are geometrical approximations of the accurate PADs (Yancey and Wood, 2000) which show possible course evasive manoeuvres at constant own velocity. Secondly, CTPAs (Collision Threat Parameters Areas) introduced by Lenart (1983), developed by Smierzchalski (2000, 2005), Szlapczynski (2006, 2007a, 2007b, 2008a, 2008b, 2009) and Szlapczynski and Smierzchalski (2009), tested by Pedersen et al. (2003) and extended for reversed solutions and other approach parameters by Lenart (1999a, 1999b, 2000a, 2000b, 2010) which show possible course and/or velocity evasive manoeuvres.

In Sections 5 to 6 collision criteria are analysed, a new collision threat parameter time to safe distance - is proposed and its application to detection of collision objects and accurate PADs is presented.

2. ASSUMPTIONS AND INPUT PARAMETERS. For the purposes of this analysis, own vessel and extraneous objects of interest are regarded as if the mass of each object was concentrated at a point. It will be assumed that all moving external objects are travelling at constant velocity and course. In the movable plane tangential to the Earth's surface Cartesian coordinates system Ox, Oy (Figure 1), with Oy pointing North, $\mathrm{O}$ is the present position of own vessel. It is also assumed that manual plots or the radar processing and tracking (ARPA) or AIS (Automatic Identification System) has yielded:

- the present relative position of each object of interest $\mathrm{X}, \mathrm{Y}$,

- the components of its true velocity $\mathrm{V}_{\mathrm{tx}}, \mathrm{V}_{\mathrm{ty}}$ and/or

- the components of its relative velocity $\mathrm{V}_{\mathrm{rx}}, \mathrm{V}_{\mathrm{ry}}$.

The relationship of own and an object's velocities can be described by equations

$$
\begin{gathered}
\mathrm{V}_{\mathrm{tx}}=\mathrm{V}_{\mathrm{rx}}+\mathrm{V}_{\mathrm{x}} \\
\mathrm{V}_{\mathrm{ty}}=\mathrm{V}_{\mathrm{ry}}+\mathrm{V}_{\mathrm{y}} \\
\mathrm{V}_{\mathrm{t}}=\sqrt{\mathrm{V}_{\mathrm{tx}}^{2}+\mathrm{V}_{\mathrm{ty}}^{2}} \\
\mathrm{~V}_{\mathrm{r}}=\sqrt{\mathrm{V}_{\mathrm{rx}}^{2}+\mathrm{V}_{\mathrm{ry}}^{2}}
\end{gathered}
$$




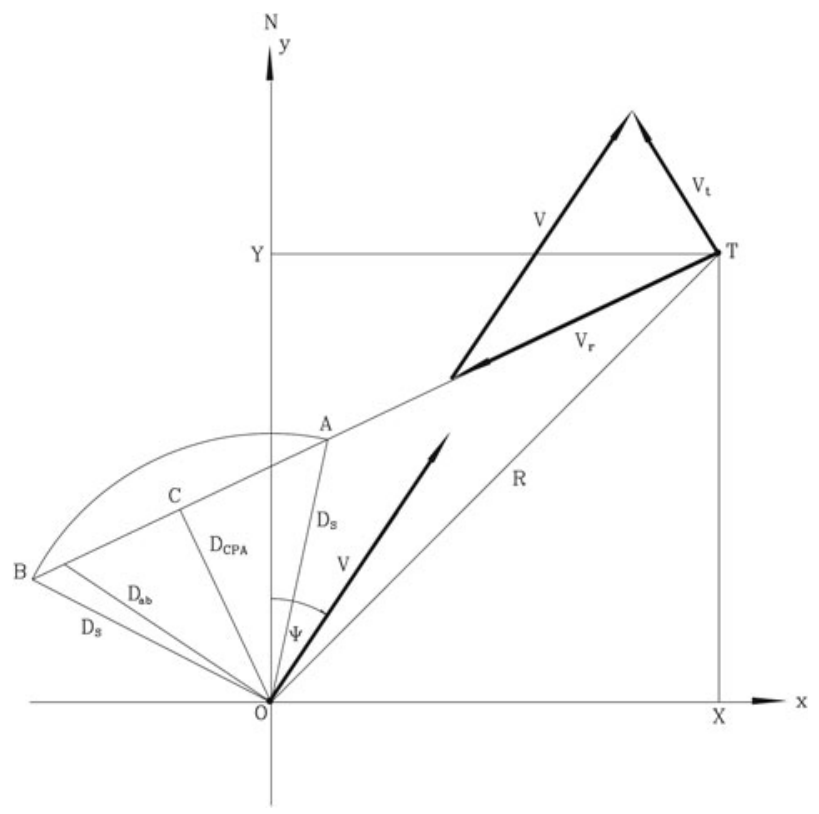

Figure 1. Input parameters.

where: $\mathrm{V}_{\mathrm{x}}, \mathrm{V}_{\mathrm{y}}-$ own velocity components,

$$
\begin{gathered}
\mathrm{V}_{\mathrm{x}}=\mathrm{V} \sin \psi \\
\mathrm{V}_{\mathrm{y}}=\mathrm{V} \cos \psi \\
\mathrm{V}=\sqrt{\mathrm{V}_{\mathrm{x}}^{2}+\mathrm{V}_{\mathrm{y}}^{2}}
\end{gathered}
$$

$\psi$-own course (the angle measured clockwise from Oy to $\mathbf{V}$ ).

From the above

$$
\begin{aligned}
\mathrm{V}_{\mathrm{tx}} & =\mathrm{V}_{\mathrm{rx}}+\mathrm{V} \sin \psi \\
\mathrm{V}_{\mathrm{ty}} & =\mathrm{V}_{\mathrm{ry}}+\mathrm{V} \cos \psi
\end{aligned}
$$

and

$$
\begin{aligned}
V_{\mathrm{rx}} & =\mathrm{V}_{\mathrm{tx}}-\mathrm{V} \sin \psi \\
\mathrm{V}_{\mathrm{ry}} & =\mathrm{V}_{\mathrm{ty}}-\mathrm{V} \cos \psi
\end{aligned}
$$

Own and an object's motion parameters should be either ground or sea referenced and drift angle is assumed to be zero.

3. EQUATIONS OF RELATIVE MOTION. The relative position of an object, at time $t$, is given by

$$
\begin{aligned}
& X(t)=X+V_{r x} t \\
& Y(t)=Y+V_{\text {ry }} t
\end{aligned}
$$


If $\mathrm{D}(\mathrm{t})$ is the distance to an object at time $\mathrm{t}$, then

$$
\mathrm{D}(\mathrm{t})=\sqrt{\mathrm{X}^{2}(\mathrm{t})+\mathrm{Y}^{2}(\mathrm{t})}=\sqrt{\mathrm{R}^{2}+\mathrm{V}_{\mathrm{r}}^{2} \mathrm{t}^{2}+2\left(\mathrm{XV}_{\mathrm{rx}}+\mathrm{YV}_{\mathrm{ry}}\right) \mathrm{t}}
$$

or after squaring both sides and rearrangements

$$
\mathrm{V}_{\mathrm{r}}^{2} \mathrm{t}^{2}+2\left(\mathrm{XV}_{\mathrm{rx}}+\mathrm{YV} \mathrm{Vy}\right) \mathrm{t}+\mathrm{R}^{2}-\mathrm{D}^{2}(\mathrm{t})=0
$$

where:

$$
\mathrm{R}=\sqrt{\mathrm{X}^{2}+\mathrm{Y}^{2}}
$$

\section{CPA DISTANCE AND TIME}

4.1. Derivation of equations for $D_{C P A}$ and $T_{C P A}$. In equation of relative motion Equation (14) the distance reaches a minimum (the Closest Point of Approach CPA) when the differential

$$
\frac{\mathrm{d}(\mathrm{t})}{\mathrm{dt}}=\frac{\mathrm{V}_{\mathrm{r}}^{2} \mathrm{t}+X \mathrm{XV}_{\mathrm{rx}}+\mathrm{YV}_{\mathrm{ry}}}{\sqrt{\mathrm{R}^{2}+\mathrm{V}_{\mathrm{r}}^{2} \mathrm{t}^{2}+2\left(\mathrm{XV}_{\mathrm{rx}}+\mathrm{YV}_{\mathrm{ry}}\right) \mathrm{t}}}=0
$$

From the above, this time $t$ is time to achieve CPA - $\mathrm{T}_{\mathrm{CPA}}$

$$
\mathrm{T}_{\mathrm{CPA}}=-\frac{\mathrm{XV}_{\mathrm{rx}}+\mathrm{YV}_{\mathrm{ry}}}{\mathrm{V}_{\mathrm{r}}^{2}}
$$

and substitution of the above time for t to Equation (14) gives distance to CPA - $\mathrm{D}_{\mathrm{CPA}}$

$$
\mathrm{D}_{\mathrm{CPA}}=\left|\frac{\mathrm{XV}_{\mathrm{ry}}-\mathrm{YV}_{\mathrm{rx}}}{\mathrm{V}_{\mathrm{r}}}\right|
$$

4.2 Analysis of equations for $D_{C P A}$ and $T_{C P A}$. $\quad \mathrm{D}_{\mathrm{CPA}}$ and $\mathrm{T}_{\mathrm{CPA}}$ are indefinable when

$$
\mathrm{V}_{\mathrm{rx}}=\mathrm{V}_{\mathrm{ry}}=\mathrm{V}_{\mathrm{r}}=0
$$

In this case according to Equations (1) and (2)

$$
\begin{aligned}
& \mathrm{V}_{\mathrm{tx}}=\mathrm{V}_{\mathrm{x}} \\
& \mathrm{V}_{\mathrm{ty}}=\mathrm{V}_{\mathrm{y}}
\end{aligned}
$$

which means that own vessel and an object are moving with the same velocities and courses and therefore the minimal distance is the same as the present distance $\mathrm{R}$

$$
\mathrm{D}_{\mathrm{CPA}}\left(\mathrm{V}_{\mathrm{rx}}=\mathrm{V}_{\mathrm{ry}}=0\right)=\mathrm{R}
$$

and

$$
\mathrm{T}_{\mathrm{CPA}}\left(\mathrm{V}_{\mathrm{rx}}=\mathrm{V}_{\mathrm{ry}}=0\right)=0
$$

Equations (18) and (19) are based on relative velocities which, when obtained from radar tracking, are more accurate than true velocities - true velocities contain errors of own velocity. 
Equation (14), after taking into consideration Equation (18), gives

$$
\mathrm{D}(\mathrm{t})=\sqrt{\mathrm{R}^{2}+\mathrm{V}_{\mathrm{r}}^{2} \mathrm{t}\left(\mathrm{t}-2 \mathrm{~T}_{\mathrm{CPA}}\right)}
$$

therefore for $\mathrm{T}_{\mathrm{CPA}}>0$

$$
\mathrm{D}(\mathrm{t}=0)=\mathrm{D}\left(\mathrm{t}=2 \mathrm{~T}_{\mathrm{CPA}}\right)=\mathrm{R}
$$

Similarly for $\mathrm{T}_{\mathrm{CPA}}<0, \mathrm{D}(\mathrm{t})$ increases with time $\mathrm{t}$, i.e., an object is moving away $-\mathrm{CPA}$ has taken place in the past.

After substituting $\mathrm{t}=\mathrm{T}_{\mathrm{CPA}}$ and $\mathrm{D}(\mathrm{t})=\mathrm{D}_{\mathrm{CPA}}$ into Equation (14) it yields

$$
\mathrm{D}_{\mathrm{CPA}}=\sqrt{\mathrm{R}^{2}-\mathrm{V}_{\mathrm{r}}^{2} \mathrm{~T}_{\mathrm{CPA}}^{2}} \quad \text { if } \quad \mathrm{R} \geq \mathrm{V}_{\mathrm{r}} \mathrm{T}_{\mathrm{CPA}}
$$

and

$$
\left|\mathrm{T}_{\mathrm{CPA}}\right|=\frac{\sqrt{\mathrm{R}^{2}-\mathrm{D}_{\mathrm{CPA}}^{2}}}{\mathrm{~V}_{\mathrm{r}}} \quad \text { if } \quad \mathrm{R} \geq \mathrm{D}_{\mathrm{CPA}}
$$

The above solutions can also be obtained by solving triangle OCT in Figure 1.

For collision avoidance purposes only present and future approaches are of interest and therefore, when

$$
\mathrm{T}_{\mathrm{CPA}}<0
$$

then for further calculations it should be assumed that

$$
\mathrm{D}_{\mathrm{CPA}}=\mathrm{R} \text { and } \mathrm{T}_{\mathrm{CPA}}=0
$$

From the above it is evident that the value of $\mathrm{D}_{\mathrm{CPA}}$ calculated from Equation (19) can be heavily corrected by the value of $\mathrm{T}_{\mathrm{CPA}}$, therefore calculation of $\mathrm{D}_{\mathrm{CPA}}$ should be inseparably connected with calculation of $\mathrm{T}_{\mathrm{CPA}}$.

It can be proved (Lenart, 2010) that the sign of formula under the modulus in Equation (19) is the sign opposite to the sign of the distance abeam $\mathrm{D}_{\mathrm{ab}}$ (Figure 1) if own course is equal to bearing to an object (when $\mathrm{T}_{\mathrm{Dab}}>0$ and $\mathrm{T}_{\mathrm{CPA}}>0$ ). Equations for this distance are derived in Lenart (2000a) - $D_{a b}>0$ means approaches on the starboard and $\mathrm{D}_{\mathrm{ab}}<0$ means approaches on the port side.

\section{COLLISION OBJECTS}

5.1. Collision criteria. Each ARPA has two settings for safe values of $\mathrm{D}_{\mathrm{CPA}}$ and $\mathrm{T}_{\mathrm{CPA}}$ preselected by an operator. It is assumed that there is a threat of collision with an object for which

$$
\mathrm{D}_{\mathrm{CPA}}<\mathrm{D}_{\mathrm{S}} \text { and } \mathrm{T}_{\mathrm{CPA}}<\mathrm{T}_{\mathrm{S}}
$$

where $D_{S}, T_{S}$ are selected safe values of $D_{C P A}$ and $T_{C P A}$ respectively.

Values $\mathrm{D}_{\mathrm{CPA}}$ and $\mathrm{T}_{\mathrm{CPA}}$ yield Equations (18) and (19), taking into consideration results of analysis in Section 4.2 i.e. if $\mathrm{V}_{\mathrm{r}}=0$ or $\mathrm{T}_{\mathrm{CPA}}<0$ we should assume

$$
\mathrm{D}_{\mathrm{CPA}}=\mathrm{R} \text { and } \mathrm{T}_{\mathrm{CPA}}=0
$$


5.2. Undetected dangerous object example. Assume a threat situation as illustrated in Figure 1 with an object $\mathrm{T}$ after passing through point $\mathrm{A}$.

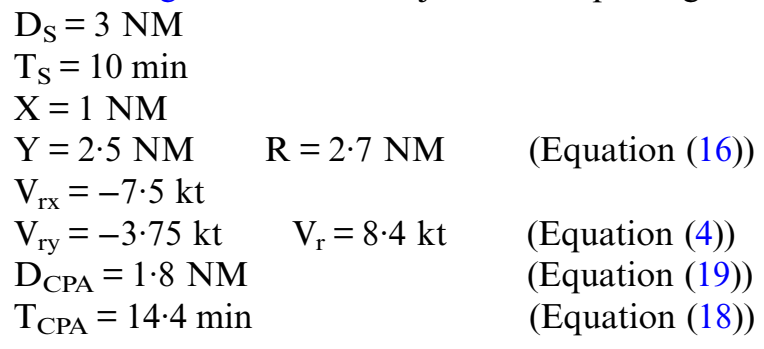

The criterion of collision threat Equation (31) classifies this object as safe $\left(\mathrm{T}_{\mathrm{CPA}}>\mathrm{T}_{\mathrm{S}}\right)$ although this object is already inside the $D_{S}$ circle $(R=2.7 N M)$, therefore this criterion should be supplemented by the next condition $-\mathrm{R}<\mathrm{D}_{\mathrm{S}}$ and Equation (31) becomes

$$
\mathrm{D}_{\mathrm{CPA}}<\mathrm{D}_{\mathrm{S}} \text { and } \mathrm{T}_{\mathrm{CPA}}<\mathrm{T}_{\mathrm{S}} \text { or } \mathrm{R}<\mathrm{D}_{\mathrm{S}}
$$

or we introduce a new collision threat parameter - time to safe distance $\mathrm{T}_{\mathrm{Ds}}$ - and a new criterion

$$
\mathrm{D}_{\mathrm{CPA}}<\mathrm{D}_{\mathrm{S}} \text { and } \mathrm{T}_{\mathrm{Ds}}<\mathrm{T}_{\mathrm{S}}
$$

\section{TIME TO SAFE DISTANCE}

6.1. Derivation of equation for $T_{D s}$. After substitution into Equation (15)

$$
\mathrm{t}=\mathrm{T}_{\mathrm{Ds}} \text { and } \mathrm{D}(\mathrm{t})=\mathrm{D}_{\mathrm{S}}
$$

we get

$$
\mathrm{V}_{\mathrm{r}}^{2} \mathrm{~T}_{\mathrm{Ds}}^{2}+2\left(\mathrm{XV}_{\mathrm{rx}}+\mathrm{YV}_{\mathrm{ry}}\right) \mathrm{T}_{\mathrm{Ds}}+\mathrm{R}^{2}-\mathrm{Ds}^{2}=0
$$

and after solving this quadratic equation in $\mathrm{T}_{\mathrm{Ds}}$

$$
\mathrm{T}_{\mathrm{Ds}}=\frac{-\left(\mathrm{XV}_{\mathrm{rx}}+\mathrm{YV}_{\mathrm{ry}}\right) \pm \sqrt{\left(\mathrm{D}_{\mathrm{S}} \mathrm{V}_{\mathrm{r}}\right)^{2}-\left(\mathrm{XV}_{\mathrm{ry}}-\mathrm{YV}_{\mathrm{rx}}\right)^{2}}}{\mathrm{~V}_{\mathrm{r}}^{2}}
$$

or according to Equations (18) and (19)

$$
\mathrm{T}_{\mathrm{Ds}}=\mathrm{T}_{\mathrm{CPA}} \pm \frac{\sqrt{\mathrm{D}_{\mathrm{s}}^{2}-\mathrm{D}_{\mathrm{CPA}}^{2}}}{\mathrm{~V}_{\mathrm{r}}}
$$

where real solutions exist if

$$
\mathrm{D}_{\mathrm{S}} \geq \mathrm{D}_{\mathrm{CPA}}
$$

Equation (38) can also be obtained by solving triangles OCA and OCB in Figure 1.

6.2. Analysis of $T_{D s}$. $\mathrm{D}_{\mathrm{CPA}}, \mathrm{T}_{\mathrm{CPA}}$ and $\mathrm{T}_{\mathrm{Ds}}$ are indeterminate when

$$
\mathrm{V}_{\mathrm{rx}}=\mathrm{V}_{\mathrm{ry}}=\mathrm{V}_{\mathrm{r}}=0
$$


In this case for collision avoidance purposes we can assume (as in Section 4.2)

$$
\mathrm{D}_{\mathrm{CPA}}=\mathrm{R} \text { and } \mathrm{T}_{\mathrm{CPA}}=0
$$

and

$$
\begin{gathered}
\mathrm{T}_{\mathrm{Ds}}=0 \text { if } \mathrm{R}<\mathrm{D}_{\mathrm{S}}(\text { collision threat }) \\
\mathrm{T}_{\mathrm{Ds}}=\infty \text { if } \mathrm{R} \geq \mathrm{D}_{\mathrm{S}}(\text { no collision threat })
\end{gathered}
$$

$\mathrm{T}_{\mathrm{Ds}}$ exists if

$$
\mathrm{D}_{\mathrm{CPA}} \leq \mathrm{D}_{\mathrm{S}}
$$

when

$$
\mathrm{D}_{\mathrm{CPA}}>\mathrm{D}_{\mathrm{S}}
$$

for collision avoidance purposes we can assume

$$
\mathrm{T}_{\mathrm{Ds}}=\infty \text { (no collision threat) }
$$

$\mathrm{T}_{\mathrm{Ds}}$, if it exists, has two values

$$
\begin{aligned}
& \mathrm{T}_{\mathrm{Ds} 1}=\mathrm{T}_{\mathrm{CPA}}-\Delta \mathrm{T}_{\mathrm{Ds}} \\
& \mathrm{T}_{\mathrm{Ds} 2}=\mathrm{T}_{\mathrm{CPA}}+\Delta \mathrm{T}_{\mathrm{Ds}}
\end{aligned}
$$

where:

$$
\Delta \mathrm{T}_{\mathrm{Ds}}=\frac{\sqrt{\mathrm{DS}_{\mathrm{S}}^{2}-\mathrm{D}_{\mathrm{CPA}}^{2}}}{\mathrm{~V}_{\mathrm{r}}}
$$

$\mathrm{T}_{\mathrm{Ds} 1}$ and $\mathrm{T}_{\mathrm{Ds} 2}$ are times to reach points $\mathrm{A}$ and $\mathrm{B}$ (Figure 1) respectively.

$\mathrm{T}_{\mathrm{Ds}}($ Equation (37)) is based on relative velocities - see also Section 4.2.

The condition

$$
\Delta \mathrm{T}_{\mathrm{Ds}} \geq \mathrm{T}_{\mathrm{S}}
$$

or

$$
\mathrm{D}_{\mathrm{S}}^{2}-\mathrm{D}_{\mathrm{CPA}}{ }^{2} \geq\left(\mathrm{V}_{\mathrm{r}} \mathrm{T}_{\mathrm{S}}\right)^{2}
$$

describes cases, when the criterion Equation (31) does not detect threat objects with $\mathrm{R}<\mathrm{D}_{\mathrm{S}}$ that is when $\mathrm{D}_{\mathrm{S}}$ is relatively big and $\mathrm{T}_{\mathrm{Ds}}$ is relatively short.

6.3. Applications of $T_{D s}$. $\mathrm{T}_{\mathrm{Ds}}$ can be used for detection of threat objects with the criterion Equation (34) taking into consideration special cases as in Section 6.2 and the following.

In the case when

$$
\mathrm{T}_{\mathrm{Ds} 1}<0 \text { and } \mathrm{T}_{\mathrm{Ds} 2}<0
$$

an object is moving away with

$$
\mathrm{R}>\mathrm{D}_{\mathrm{S}}
$$

and this is after reaching point $\mathrm{B}$ and therefore

$$
\mathrm{T}_{\mathrm{Ds}}=\infty(\text { no collision threat })
$$


In the case when

$$
\mathrm{T}_{\mathrm{Ds} 1} \mathrm{~T}_{\mathrm{Ds} 2} \leq 0
$$

an object is between points A and B and therefore

$$
\mathrm{R} \leq \mathrm{D}_{\mathrm{S}} \text { and } \mathrm{T}_{\mathrm{Ds}}=0(\text { collision threat })
$$

In the case when

$$
\mathrm{T}_{\mathrm{Ds} 1}>0 \text { and } \mathrm{T}_{\mathrm{Ds} 2}>0
$$

an object is approaching with

$$
\mathrm{D}_{\mathrm{CPA}}<\mathrm{D}_{\mathrm{s}}
$$

and is not yet at point A. Thus

$$
\mathrm{T}_{\mathrm{Ds}}=\mathrm{T}_{\mathrm{Ds} 1}
$$

and an object is dangerous if

$$
\mathrm{T}_{\mathrm{Ds}}<\mathrm{T}_{\mathrm{S}}
$$

This time $\mathrm{T}_{\mathrm{Ds}}$ according to Equations (59) and (47) is shorter than $\mathrm{T}_{\mathrm{CPA}}$ (which can be time to collision) and therefore the criterion Equation (34) is safer than Equation (33) or $T_{S}$ can be shorter than used in the criterion Equation (33).

The above algorithm may seem complex because it combines calculating $\mathrm{R}, \mathrm{D}_{\mathrm{CPA}}$, $\mathrm{T}_{\mathrm{Ds}}$ with the detection of dangerous objects. However in collision avoidance systems the detection of dangerous objects (which is made for all objects), can be much simpler than the calculation of all threat parameters (which is made for one or a few selected objects only). In fact, the criterion Equation (34) is easier to apply than Equation (33), because it mostly involves processing signs only (Section 6.3), whereas in case of the criterion Equation (33) $\mathrm{D}_{\mathrm{CPA}}, \mathrm{T}_{\mathrm{CPA}}$ values have to be computed, checked and possibly replaced with the values from Equation (32).

In the undetected dangerous object example (Section 5.2) application of $\mathrm{T}_{\mathrm{Ds}}$ gives: $\Delta \mathrm{T}_{\mathrm{Ds}}=17 \cdot 1 \mathrm{~min} \quad$ (Equation (49))

$\mathrm{T}_{\mathrm{Ds} 1}=-2 \cdot 7 \mathrm{~min} \quad$ (Equation (47))

$\mathrm{T}_{\mathrm{Ds} 2}=31.5 \mathrm{~min} \quad$ (Equation (48))

$\mathrm{T}_{\mathrm{Ds}}=0 \quad$ (Equation (56))

and according to the criterion Equation (34) an object is classified as dangerous (independently of $\mathrm{T}_{\mathrm{S}}$ ). See also condition Equation (50).

For the given own velocity $\mathrm{V}$ (real or simulated), a variable own course $\psi$ and constant object's true velocity components $\mathrm{V}_{\mathrm{tx}}, \mathrm{V}_{\mathrm{ty}}$, we can calculate $\mathrm{V}_{\mathrm{rx}}, \mathrm{V}_{\mathrm{ry}}$ from Equations (10) and (11).

For own courses $\psi$, for which (for all tracked objects)

$$
\mathrm{D}_{\mathrm{CPA}} \leq \mathrm{D}_{\mathrm{S}}
$$

we can calculate values $\mathrm{T}_{\mathrm{Ds} 1}, \mathrm{~T}_{\mathrm{Ds} 2}$ (Equations (47)-(49)) and $\mathrm{V}_{\mathrm{x}}, \mathrm{V}_{\mathrm{y}}$ from Equations (5) and (6). By plotting positions of points

$$
\begin{aligned}
& \left(\mathrm{x}=\mathrm{V}_{\mathrm{x}} \mathrm{T}_{\text {Ds1 } 1}, \mathrm{y}=\mathrm{V}_{\mathrm{y}} \mathrm{T}_{\text {Ds1 }}\right) \\
& \left(\mathrm{x}=\mathrm{V}_{\mathrm{x}} \mathrm{T}_{\text {Ds2 } 2}, \mathrm{y}=\mathrm{V}_{\mathrm{y}} \mathrm{T}_{\text {Ds2 }}\right)
\end{aligned}
$$




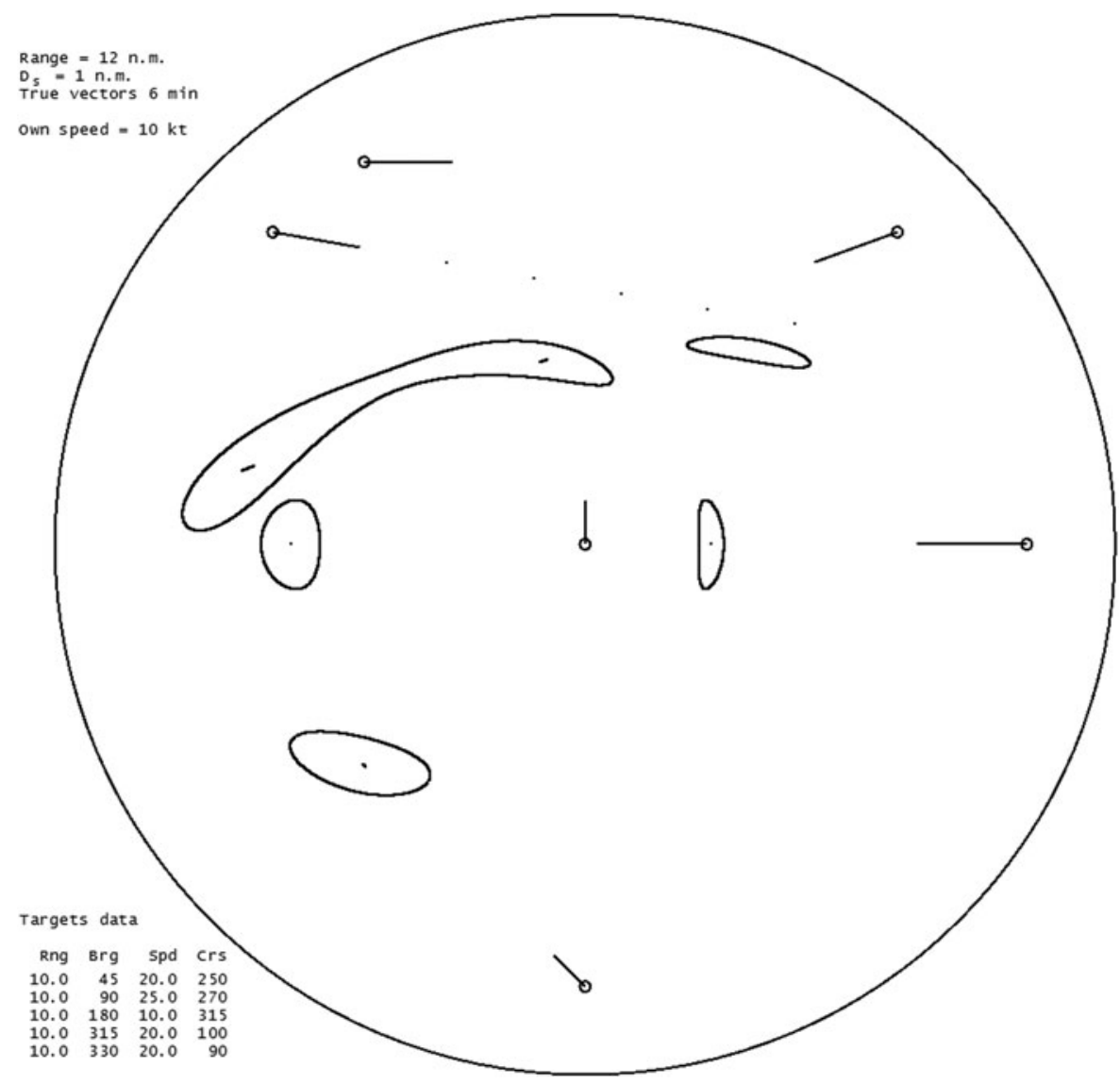

Figure 2. Accurate Predicted Areas of Danger.

we obtain boundaries of areas, for which own courses are leading to

$$
\mathrm{D}_{\mathrm{CPA}} \leq \mathrm{D}_{\mathrm{S}}
$$

These are accurate PADs similar to Yancey and Wood (2000) but obtained by a much simpler method.

Figure 2 illustrates exemplary accurate PADs plotted using parameter $\mathrm{T}_{\mathrm{Ds}}$. Points inside PADs are PPCs (Predicted Points of Collision) for which $\mathrm{D}_{\mathrm{CPA}}=0$. Attention should be drawn to the object at bearing $315^{\circ}$, which does not have a PPC and its PAD lies entirely out of its true course line.

7. CONCLUSIONS. It has been proved that derived equations for $\mathrm{D}_{\mathrm{CPA}}$ and $\mathrm{T}_{\mathrm{CPA}}$ have special cases and new features and collision criteria have limitations. A new collision threat parameter - time to safe distance - may have various applications. It can be applied to detection of dangerous objects, solving the problem of undetected dangerous objects, and giving safer time to dangerous situations than the time to CPA, which can be time to collision. It can be applied also to display the possible evasive manoeuvres (accurate PADs instead of their geometrical approximations). 


\section{REFERENCES}

Cornett, J.A., Gentry, H.S., Seay, W.M., Tucker, T.A and Wigent, D.J. (1979). PPI Display for Radar and Synthetic Symbology. Patent US 4224621.

Fleischer, H.J., Lipsky, P. and Tiblin, B.V. (1970). Collision Avoidance Display Apparatus for Maneuverable Craft. Patent US 3725918.

Fleischer, H.J., Lipsky, P. and Tiblin, B.V. (1971). Collision avoidance apparatus. Patent GB 1366718-A.

Jakševič, E.V. (1967). Algoritm posledovatel'noj obrabotki radiolokacionnych izmerenij. Trudy CNIMFSudovoždenie i svjaz', 83, 58-63.

Lenart, A.S. (1983). Collision Threat Parameters for a New Radar Display and Plot Technique. Journal of Navigation, 36, 404-410.

Lenart, A.S. (1999a). Manoeuvring to Required Approach Parameters - CPA Distance and Time. Annual of Navigation, 1, 99-108.

Lenart, A.S. (1999b). Manoeuvring to Required Approach Parameters - Distance and Time on Course. Annual of Navigation. 1, 109-115.

Lenart, A.S. (2000a). Manoeuvring to Required Approach Parameters - Distance and Time Abeam. Annual of Navigation. 2, 81-88.

Lenart, A.S. (2000b). Manoeuvring to Required Approach Parameters - Distance, Time and Bearings. Annual of Navigation. 2, 89-97.

Lenart, A.S. (2010). Approach Parameters in Marine Navigation - Theory and Applications. Gdynia Maritime University Publishing.

Lord, R.N. (1968). A Controlled Azimuth Avoidance Manoeuvre. Journal of the Institute of Navigation, 21, 171-181.

Pedersen, E., Inoue, K. and Tsugane, M. (2003). Simulator Studies on a Collision Avoidance Display that Facilitates Efficient and Precise Assessment of Evasive Manoeuvres in Congested Waterways. Journal of Navigation, 56, 411-427.

Riggs, R.F. (1970). Ship's Maneuver Assessment System. Patent US 3717873.

Riggs, R.F. (1975). A Modern Collision Avoidance Display Technique. Journal of Navigation, 28, 143-155.

Riggs, R.F. and O'Sullivan, J.P. (1980). An Analysis of the Point of Possible Collision. Journal of Navigation, 33, 259-283.

Smierzchalski, R. (2000). Ships' domains as a collision risk at sea in the evolutionary trajectory planning. International Conference on Computer Simulation in Risk Analysis and Hazard Mitigation No 2, Bologna Italy, 43-52.

Smierzchalski, R. (2005). Ships' domains as collision risk at sea in the evolutionary method of trajectory planning. Information Processing and Security Systems, Springer, XII, 411-422.

Szlapczynski, R. (2006). A Unified Measure Of Collision Risk Derived From The Concept Of A Ship Domain. Journal of Navigation, 59, 477-490.

Szlapczynski, R. (2007a). Fuzzy Collision Threat Parameters Area (FCTPA) - a new display proposal. Advances in Marine Navigation and Safety of Sea Transportation - TransNav'2007, Gdynia, Poland, 213-218.

Szlapczynski, R. (2007b). Determining the Optimal Course Alteration Manoeuvre in a Multi-target Encounter Situation for a Given Ship Domain Model. Annual of Navigation, 12, 75-85.

Szlapczynski, R. (2008a). A New Method Of Planning Collision Avoidance Manoeuvres For Multitarget Encounter Situations. Journal of Navigation, 61, 307-321.

Szlapczynski, R. (2008b). Fuzzy Collision Threat Parameters Area (FCTPA) - a new display proposal. TransNav-International Journal on Marine Navigation and Safety of Sea Transportation, 2(4), 359-362.

Szlapczynski, R. and Smierzchalski, R. (2009). Supporting navigator's decisions by visualizing ship collision risk. Polish Maritime Research, 16(1), 83-90.

Szlapczynski, R. (2009). Planning Emergency Manoeuvres. Journal of Navigation, 62, 79-91.

Yancey, J.F., Jr. and Wood, T.E. (2000). Apparatus and Method Providing Accurate Boundaries Predicted Areas of Danger for Collision Avoidance. Patent US 6408248 B1. 